\title{
KAPSULIŲ SU DIKLOFENAKO NATRIO DRUSKA MODELIAVIMAS IR KOKYBESS VERTINIMAS
}

\author{
Laura Paškevičiūte் ${ }^{2}$, Asta Marija Inkẻnienè $\dot{1}^{1,2}$, Kristina Ramanauskiené2 \\ ${ }^{1}$ Kauno kolegijos Medicinos fakulteto Farmakotechnikos katedra, \\ ${ }^{2}$ Lietuvos sveikatos mokslu universiteto Klinikinès farmacijos katedra
}

\begin{abstract}
Raktažodžiai: diklofenako natrio druska, pagalbinès medžiagos, suirimo testas, tirpimo testas, natrio karboksimetilceliuliozè.
\end{abstract}

\begin{abstract}
Santrauka
Diklofenako natrio druska yra nesteroidinis vaistas nuo uždegimo, sunkiai tirpstantis vandenyje. Aktualu pagaminti negreito tirpimo kapsules su diklofenako natrio druska, padedančias išvengti dirginančio poveikio virškinamojo trakto gleivinei ir užtikrinti diklofenako druskos tirpumą virškinamojo kanalo skysčiuose. Mūsų tyrimams pasirinkta farmacinè forma kapsulès yra viena iš plačiausiai vartojamų geriamujjų farmacinių formų. Gaminant kietają farmacinę formą, svarbu parinkti tinkamas pagalbines medžiagas, kurios užtikrintų tinkamą vaistinès medžiagos tirpimo kinetiką. Kapsuliuojamojo mišinio užpildui naudotas mikrokristalinès celiuliozès ir silicio dioksido mišinys (Prosolv SMCC ${ }^{\mathrm{TM}}$ 50), D-manitolis ir D-(+)-gliukozè. Natrio karboksimetilceliuliozè kapsuliuojamojo mišinio gamyboje naudota kaip vaistinès medžiagos atpalaidavimą ilginanti medžiaga. Suirimo ir tirpimo testai atlikti naudojantis Europos farmakopejoje (Ph. Eur.) pateiktomis tyrimo metodikomis. Diklofenako natrio druskos kiekis nustatytas spektrofotometriniu metodu. Pagamintos devyniu sudèčių kapsulès, turinčios skirtingą natrio karboksimetilceliuliozès kiekị (0-35\%), siekiant pailginti veikliosios medžiagos atpalaidavimo laiką. Tyrimo rezultatai parodè, kad natrio karboksimetilceliuliozé yra tinkama pagalbinè medžiaga, siekiant pailginti kapsulès veikliosios medžiagos atpalaidavimo laiką. Diklofenako natrio druskos atpalaidavimo ir kapsulių suirimo laikas priklauso nuo natrio karboksimetilceliuliozès kiekio kapsulèje.
\end{abstract}

\section{Ivadas}

Diklofenakas priklauso nesteroidinių vaistų nuo uždegimo (NVNU) grupei [1]. Šios grupès vaistai mažina skausmą, karščiavimą bei uždegimą. NVNU blokuoja ciklooksigenazių sintezę, todèl mažeja uždegiminių mediatorių išsiskyrimas, o skausmas malšinamas greitai ir efektyviai. Svarbiausios šiame procese yra dvi ciklooksigenazès formos - tai ciklooksigenazè-1 (COX-1) ir ciklooksigenazè-2 (COX2) [2]. COX-1 dalyvauja prostaglandinų sintezejje, todèl šio fermento sintezès blokavimas slopina bikarbonatų sekreciją ir skrandžio gleivių gamybą, mažina virškinamojo kanalo gleivinès kraujotaką ir epitelio proliferaciją, slopina trombocitu agregaciją, blogina inkstų kraujotaką. Siekiant sumodeliuoti geriamąsias kapsules su diklofenako natrio druska, reikia atsižvelgti ị tai, kad dèl šios medžiagos poveikio virškinimo kanalui dideja opų išsivystymo rizika bei galimas kraujavimas iš jų. Diklofenako natrio druska pagal vaistinių medžiagų biofarmacinę klasifikacijos sistemą (BKS) priklauso 2 klasei medžiagų, kurios pasižymi blogu tirpumu ir geru skvarbumu per biologines membranas [3]. Mokslinejje literatūroje 2 klasės vaistai pagal BKS vadinami „blogai tirpiais“ dèl jų mažo tirpumo skrandžio terpejje [4,5], tačiau šie vaistai gali visiškai ištirpti plonosios žarnos skysčiuose. Diklofenako natris praktiškai netirpsta vandenyje $(\sim 3,6 \mu \mathrm{g} / \mathrm{ml})$, bet tirpsta žarnyno skystyje ( $\sim 26 \mathrm{mg} / \mathrm{ml})$. Aktualu pagaminti pailginto atpalaidavimo kapsules su diklofenako natrio druska, kad būtų užtikrintas diklofenako druskos tirpumas virškinamojo kanalo skysčiuose ir išvengta dirginančio poveikio dèl per trumpą laiką iš vaisto formos atpalaiduojamos didelès vaistinès medžiagos koncentracijos ( 85 proc. ir daugiau/15 min). Svarbus kietų farmacinių formų modeliavimo etapas yra formos kategorijos parinkimas. Moksliniais tyrimais įrodyta, kad farmaciné forma ir pasirinktos pagalbinès medžiagos daro įtaką vaistinès medžiagos biologiniam pasisavinimui [6]. Mūsų tyrimams pasirinkta farmacinè forma - kapsulès yra viena iš plačiausiai vartojamų geriamujų farmacinių formų. Gaminant kietą farmacinę formą, svarbu parinkti 
tinkamas pagalbines medžiagas, kurios užtikrintų tinkamą vaistinès medžiagos tirpimo kinetiką. Kapsuliuojamojo mišinio sudètyje užpildui naudotas mikrokristalinès celiuliozès ir silicio dioksido mišinys, D-manitolis arba D-(+)-gliukozė. Natrio karboksimetilceliuliozė kapsuliuojamojo mišinio gamyboje naudota kaip vaistinès medžiagos atpalaidavimą ilginanti medžiaga.

Šio darbo tikslas - sumodeliuoti kapsules su diklofenako natrio druska ir įvertinti pagalbinių medžiagų poveiki vaistinès medžiagos tirpimo kinetikai iš farmacinès formos.

\section{Tyrimo medžiaga ir metodai}

Suirimo testas. Kapsulių suirimo laikas nustatytas remiantis Ph. Eur. 2.9.1 metodika. Suirimo laikui nustatyti naudotas aparatas ADINT-2, MRC LTD. Suirimo terpe - 0,1 $M$ vandenilio chlorido rūgšties tirpalas, temperatūra $37 \pm 0,5$ ${ }^{0} \mathrm{C}$, stebima $30 \mathrm{~min}$.

Tirpimo testas. Atliktas mentiniu prietaisu (Ph. Eur. 2.9.3.). Tirpimo terpe - išgrynintas vanduo, tūris $500 \mathrm{ml}$, mentès apsisukimų dažnis iki $100 \mathrm{aps/min.} \mathrm{Terpès} \mathrm{tempera-}$

1 lentelė. Miltelių birumo vertinimas pagal Hausner koeficientą ir Carr's indeksą.

\begin{tabular}{|l|c|c|}
\hline $\begin{array}{l}\text { Miltelių } \\
\text { birumas }\end{array}$ & $\begin{array}{c}\text { Hausner koefi- } \\
\text { cientas }\end{array}$ & Carr's indeksas \\
\hline Puikus & $1-1,11$ & $<10$ \\
\hline Geras & $1,12-1,18$ & $11-15$ \\
\hline Tinkamas & $1,19-1,25$ & $16-20$ \\
\hline Neblogas & $1,26-1,34$ & $21-25$ \\
\hline Blogas & $1,34-1,45$ & $26-31$ \\
\hline Labai blogas & $1,46-1,59$ & $32-37$ \\
\hline
\end{tabular}

tūra palaikoma $37 \pm 0,5^{\circ} \mathrm{C}$. Mèginiai imti po $15,30,45,60$, 75 ir 90 min. po $1 \mathrm{ml}$, pakeičiant išimtą kiekị šviežia tirpimo terpe. Išsiskyręs diklofenako natrio kiekis nustatomas $1 \mathrm{ml}$ mėginio praskiedžiant iki $25 \mathrm{ml}$ ir matuojant absorbciją 275 $\mathrm{nm}$ bangos ilgyje Agilent $8453 \mathrm{UV}$-Vis spektrofotometru. Diklofenako koncentracija nustatyta pagal sudarytą kalibracinę kreivę.

Masès vienodumo testas. Tiriamosios kapsulès pasveriamos ir nustatoma vidutinė 1 kapsulès masè (Ph. Eur. 2.9.5). Sveriama 1 kapsulè, išberiamas jos turinys ir pasveriamas kapsulių apvalkalas. Apskaičiuojama turinio masè, t.y. skirtumas tarp kapsulès masès ir apvalkalo masès. Tokia procedūra taikoma kiekvienai modeliuojamai kapsulei. Leistinas nuokrypis $300 \mathrm{mg}$ kapsulèms yra 7,5 procento.

Hausner santykio ir Carr's indekso rodiklių nustatymas. Hausner santykis išreiškiamas santykiu tarp miltelių tūrio ir sutankintų miltelių tūrio. 1 lentelèje parodyta, kaip Hausner santykis ir Carr's (suspaudžiamumo) indeksas charakterizuoja miltelių birumą [7].

Carr's indeksas apskaičiuojamas pagal formulę:

$$
C=100 \frac{V_{B}-V_{T}}{V_{B}}, \text { kur } \mathrm{V}_{\mathrm{B}} \text { - laisvasis miltelių tūris; }
$$

Statistinė analizė. Statistinè duomenų analizè atlikta naudojant IBM SPSS Statistics 20 programinę įrangą.

\section{Tyrimo rezultatai ir jų aptarimas}

Pirmajame tyrimų etape buvo pasirinktos pagalbinès medžiagos kapsulių turinio modeliavimui. Pagalbinès medžiagos pasirinktos kaip priemonè, padedanti sumodeliuoti farmacinę formą ir užtikrinanti kokybišką vaistinès medžiagos atpalaidavimą iš formos [8]. Sumodeliuotų kapsulių sudètis pateikiama 2 lentelèje.

\begin{tabular}{|c|c|c|c|c|c|c|c|}
\hline Grupė & $\begin{array}{l}\text { Tiria- } \\
\text { masis } \\
\text { pavyz- } \\
\text { dys }\end{array}$ & $\begin{array}{l}\text { Diklofe- } \\
\text { nako na- } \\
\text { trio druska } \\
\text { (mg) }\end{array}$ & $\begin{array}{l}\text { Natrio kar- } \\
\text { boksimetil- } \\
\text { celiuliozė } \\
\text { (mg) }\end{array}$ & $\begin{array}{l}\text { D-(+)- } \\
\text { gliukozès } \\
\text { monohi- } \\
\text { dratas }\end{array}$ & $\begin{array}{l}\text { D-ma- } \\
\text { nitolis }\end{array}$ & $\begin{array}{c}\text { Prosolv SMCC } \\
50 \text { (mikrokris- } \\
\text { talinė celiuliozé, } \\
\text { koloidinis silicio } \\
\text { dioksidas) }\end{array}$ & $\begin{array}{l}\text { Ben- } \\
\text { droji } \\
\text { masé, } \\
\text { mg }\end{array}$ \\
\hline \multirow{4}{*}{ I gr. } & N1 & 100 & 50 & 0 & 0 & 150 & 300 \\
\hline & N2 & 100 & 75 & 0 & 0 & 125 & 300 \\
\hline & N3 & 100 & 90 & 0 & 0 & 110 & 300 \\
\hline & N4 & 100 & 105 & 0 & 0 & 95 & 300 \\
\hline \multirow{2}{*}{ II gr. } & N5 & 100 & 90 & 110 & 0 & 0 & 300 \\
\hline & N6 & 100 & 90 & 0 & 110 & 0 & 300 \\
\hline \multirow{3}{*}{ III gr. } & N7 & 100 & 0 & 200 & 0 & 0 & 300 \\
\hline & N8 & 100 & 0 & 0 & 200 & 0 & 300 \\
\hline & N 9 & 100 & 0 & 0 & 0 & 200 & 300 \\
\hline
\end{tabular}

2 lentelè. Kapsulių su diklofenako natrio druska sudètis. 
Pagaminti kapsuliuojamieji mišiniai suskirstyti ị tris grupes (2 lentelè). I kiekvieną kapsuliuojamaji mišinį įberiama 100 mg diklofenako natrio druskos ir $200 \mathrm{mg}$ pagalbinių medžiagų. Siekiant užtikrinti tinkamą miltelių mišinio birumą ir tikslų dozavimą į kapsules, kapsuliuojamojo mišinio užpildui naudota gliukoze, manitolis ir mikrokristalinès celiuliozès mišinys. Veikliosios medžiagos atpalaidavimui lètinti naudota natrio karboksimetilceliuliozè $[9,10]$.

Miltelių birumas yra pagrindinis reikalavimas kietų farmacinių formų vaistų gamybos procesui. Miltelių birumo įvertinimui nustatytas milteliams būdingas Carr's indeksas ir Hausner santykis. Šie rodikliai apibūdina medžiagų birumą [12]. Birumas yra svarbus kapsuliuojamojo mišinio kokybės vertinimo kriterijus, nuo jo priklauso tikslus mišinio dozavimas ị kapsules. Tyrimo rezultatai pateikti 1 ir 2 paveiksluose.

Tyrimų rezultatai parodè, kad diklofenako natrio druska pasižymi blogu birumu, nustatytas Carr's indeksas 29, o Hausner santykis - 1,4, todèl pagalbinių medžiagų naudojimas yra būtinas, siekiant pagaminti

3 lentelè. Kapsulių su 100 mg diklofenako natrio druska kokybės rodikliai.

\begin{tabular}{|c|c|c|c|c|c|c|c|c|}
\hline \multirow[t]{2}{*}{$\begin{array}{l}\text { Milte- } \\
\text { liụ mi- } \\
\text { šiniụ } \\
\text { grupė }\end{array}$} & \multirow[t]{2}{*}{$\begin{array}{l}\text { Kap- } \\
\text { sulių } \\
\text { serija }\end{array}$} & \multirow[t]{2}{*}{$\begin{array}{l}\text { Pripildymo } \\
\text { kokybė }\end{array}$} & \multicolumn{3}{|c|}{$\begin{array}{l}\text { Vidutinė masė } \\
\text { (g) }\end{array}$} & \multicolumn{3}{|c|}{$\begin{array}{l}\text { Suirimo } \\
\text { laikas } \\
\text { (min.) } \\
\text { Terpé } \mathrm{HCl}\end{array}$} \\
\hline & & & 1 & 2 & 3 & 1 & 2 & 3 \\
\hline \multirow{4}{*}{ I gr. } & N1 & $\begin{array}{l}\text { Mase biri, } \\
\text { kapsule pripil- } \\
\text { doma pilna }\end{array}$ & 0,303 & 0,301 & 0,304 & 18 & 16 & 17 \\
\hline & N2 & $\begin{array}{l}\text { Masè biri, } \\
\text { kapsulè pripil- } \\
\text { doma pilna }\end{array}$ & 0,291 & 0,295 & 0,293 & 20 & 18 & 19 \\
\hline & N3 & $\begin{array}{l}\text { Masė biri, } \\
\text { kapsule pripil- } \\
\text { doma pilna }\end{array}$ & 0,298 & 0,304 & 0,2 & 22 & 21 & 22 \\
\hline & N4 & $\begin{array}{l}\text { Masè biri, } \\
\text { kapsule pripil- } \\
\text { doma pilna }\end{array}$ & 0,303 & 0,291 & 0,302 & 26 & 27 & 26 \\
\hline \multirow{2}{*}{ II gr. } & N5 & $\begin{array}{l}\text { Mase biri, } \\
\text { kapsule pripil- } \\
\text { doma pilna }\end{array}$ & 0,293 & 0,296 & 0,290 & 16 & 18 & 19 \\
\hline & N6 & $\begin{array}{l}\text { Masė biri, } \\
\text { kapsulè pripil- } \\
\text { doma pilna }\end{array}$ & 0,298 & 0,299 & 0,297 & 15 & 17 & 19 \\
\hline \multirow{3}{*}{ III gr. } & N7 & $\begin{array}{l}\text { Masė biri, } \\
\text { kapsulè pripil- } \\
\text { doma pilna }\end{array}$ & 0,295 & 0,294 & 0,290 & 3 & 4 & 4 \\
\hline & N8 & $\begin{array}{l}\text { Mase biri, } \\
\text { kapsulè pripil- } \\
\text { doma pilna }\end{array}$ & 0,297 & 0,294 & 0,291 & 5 & 4 & 5 \\
\hline & N9 & $\begin{array}{l}\text { Mase biri, } \\
\text { kapsule pripil- } \\
\text { doma pilna }\end{array}$ & 0,294 & 0,291 & 0,290 & 5 & 5 & 5 \\
\hline
\end{tabular}

tinkamo birumo kapsuliuojamuosius mišinius. Pagal Hausner santykị ir Carr's indeksą, puikiu birumu pasižymi N7-N9 kapsuliuojamieji milteliu mišiniai (1,2 pav). Miltelių mišiniams, kurių sudètyje yra natrio karboksimetilceliuliozès (N1-N6), būdingas geras birumas. Apibendrinant galima teigti, kad visų miltelių mišinių birumas neturètų daryti neigiamos itakos kapsuliavimo procesui.

Pagamintų kapsulių kokybė vertinta pagal šiuos parametrus: masès vienodumas, suirimo laikas, iš kapsulès išsiskyręs vaistinès medžiagos kiekis (tirpimo testas). 3 lentelèje pateikti duomenys parodè, kad kapsulių masès vienodumo rodikliai yra panašūs. Galima teigti, kad pasirinktos pagalbinès medžiagos ir jų kiekiai užtikrina tikslų kapsuliuojamojo mišinio dozavimą į kapsules.

Kitame tyrimų etape vertintas kapsulių suirimas ir tirpimas. Tirpimo ir suirimo testai in vitro yra svarbūs kapsulių kokybės vertinimo rodikliai. Remiantis šių testų rezultatais, galima prognozuoti modeliuojamų kapsulių biologini pasisavinamumą. Suirimo testo rezultatai parodè (3 lentelè), kad kapsulès N7-N9 suyra greičiausiai (iki $5 \mathrm{~min}$ ). Europos farmakopejja nurodo, kad nemodifikuoto

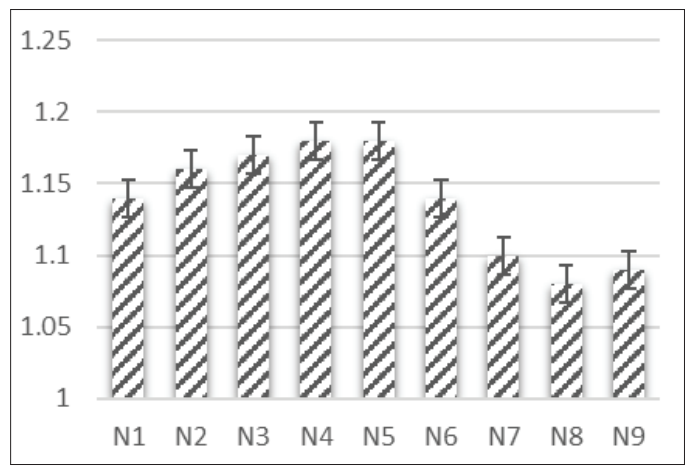

1 pav. Hausner santykio rezultatai.

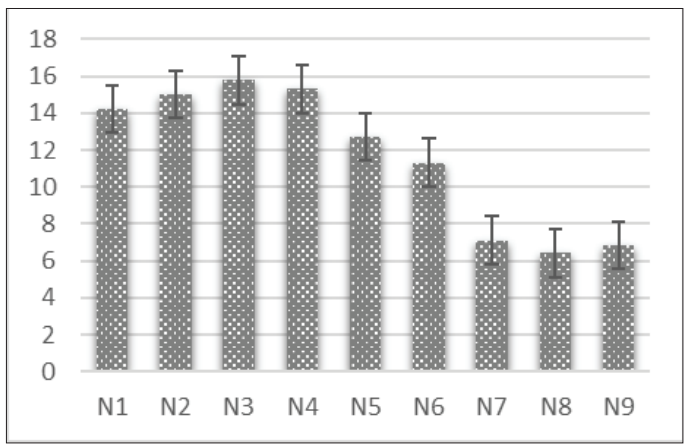

2 pav. Carr's indekso nustatymo rezultatai. 
veikimo kapsulès turi suirti per 30 min., todèl galima teigti, kad kapsulès N7-N9 atitinka keliamus reikalavimus [11]. Kapsulių, kurių sudètyje yra prolonguojančių medžiagų (N1N6), suirimo laikas terpejje svyruoja nuo 15 iki 26 minučių. Nustatyti statistiškai reikšmingi I, II ir III miltelių mišinių grupių suirimo laiko skirtumai $(\mathrm{p}<0,05)$. Tyrimo rezultatai parodè, kad pagalbinès medžiagos daro ịtaką kapsulių suirimo laikui. Natrio karboksimetilceliuliozè yra tinkamas komponentas modeliuoti pailginto veikimo farmacines formuluotes [12].

3 paveiksle pateikti tyrimo duomenys parodo, kad greičiausiai atpalaiduojama vaistinè medžiaga iš III grupès miltelių mišinių kapsulių, kurių sudètyje nèra natrio karboksimetilceliuliozès. Pagal tirpimo testo tyrimo rezultatus, šios grupès kapsules galima priskirti labai greito tirpimo preparatams, nes per 15 minučiu buvo atpalaiduota daugiau nei 85 proc. veikliosios medžiagos. Statistiškai reikšmingo skirtumo tarp III grupès kapsulių sudèties nèra $(\mathrm{p}>0,05)$, todèl galima teigti, kad visi naudoti užpildai yra tinkami naudojimui. Eksperimentinių tyrimų metu nustatyta, kad didejjant natrio karboksimetilceliuliozès kiekiui, vaistinès medžiagos išskyrimas iš kapsulių lètèja. Nustatyta, kad 15-60 minučių intervale mažiausią kiekị diklofenako natrio druskos atpalaiduoja N3 ir N4 kapsulès, kurių sudètyje natrio karboksimetilceliuliozès yra 90 ir 105 mg. Iš visų I grupès kapsulių po 75 minučiu atpalaiduojama daugiau nei 85 proc. veikliosios medžiagos. Nenustatytas statistiškai reikšmingas skirtumas tarp atpalaiduoto kiekio diklofenako natrio druskos iš I grupès kapsulių po 90 minučių ( $\mathrm{p}>0,05$ ), tačiau nustatytas statistiškai reikšmingas skirtumas tarp N1, N2 ir N3, N4 15-60 minučių laiko intervale $(\mathrm{p}<0,05)$. Iš II grupès kapsulių vaistinès medžiagos atpalaidavimas vyksta greičiau, nei iš I grupès. Iš kapsulių N5 veikliosios medžiagos per 85 proc. atpalaiduojama po 1 valandos, o iš kapsulių N6 - po 75 minučių. Po 15 ir po 90 minučių statistiškai reikšmingo skirtumo tarp N5 ir N6 kapsulių nenustatyta ( $p>0,05)$, tačiau po 30 minučių nustatytas statistiškai reikšmingas skirtumas $(p<0,05)$. Tyrimų rezultatai parode, kad vaistinès medžiagos atpalaidavimo kinetika priklauso ne tik nuo natrio karboksimetilceliuliozès kiekio, bet ir nuo pasirinkto užpildo. Kai kapsulių užpildas yra Prosolv SMCC ${ }^{\mathrm{TM}} 50$, gliukozè ar D-manitolis, sumodeliuotos kapsulès pasižymi labai greitu tirpimu, nes po 15 minučių atpalaiduojama daugiau nei 85 proc. veikliosios medžiagos [4].

Gaminant pailginto atpalaidavimo kapsules su diklofenako natrio druska, užpildui geriau naudoti mikrokristalinès celiuliozès mišinį, taip užtikrinant tolygų vaistinès medžiagos atpalaidavimą ir tirpumą fiziologiniuose skysčiuose 1,5 val. laikotarpiu, kai natrio karboksimetilceliuliozè sudaro 30 proc. nuo bendrosios kapsulès masès.

\section{Išvados}

1. Pasirinktos pagalbinès medžiagos užtikrino miltelių mišinio tinkamas technologines savybes ir tikslų dozavimą i kapsules. Natrio karboksimetilceliuliozė yra tinkamas komponentas modeliuoti kapsules su diklofenako natrio druska, kai siekiama pailginti veikliosios medžiagos atpalaidavimą.

2. Natrio karboksimetilceliuliozès kiekis kapsulèje lètina diklofenako natrio atpalaidavimo greitị ir kapsulių suirimo laiką.
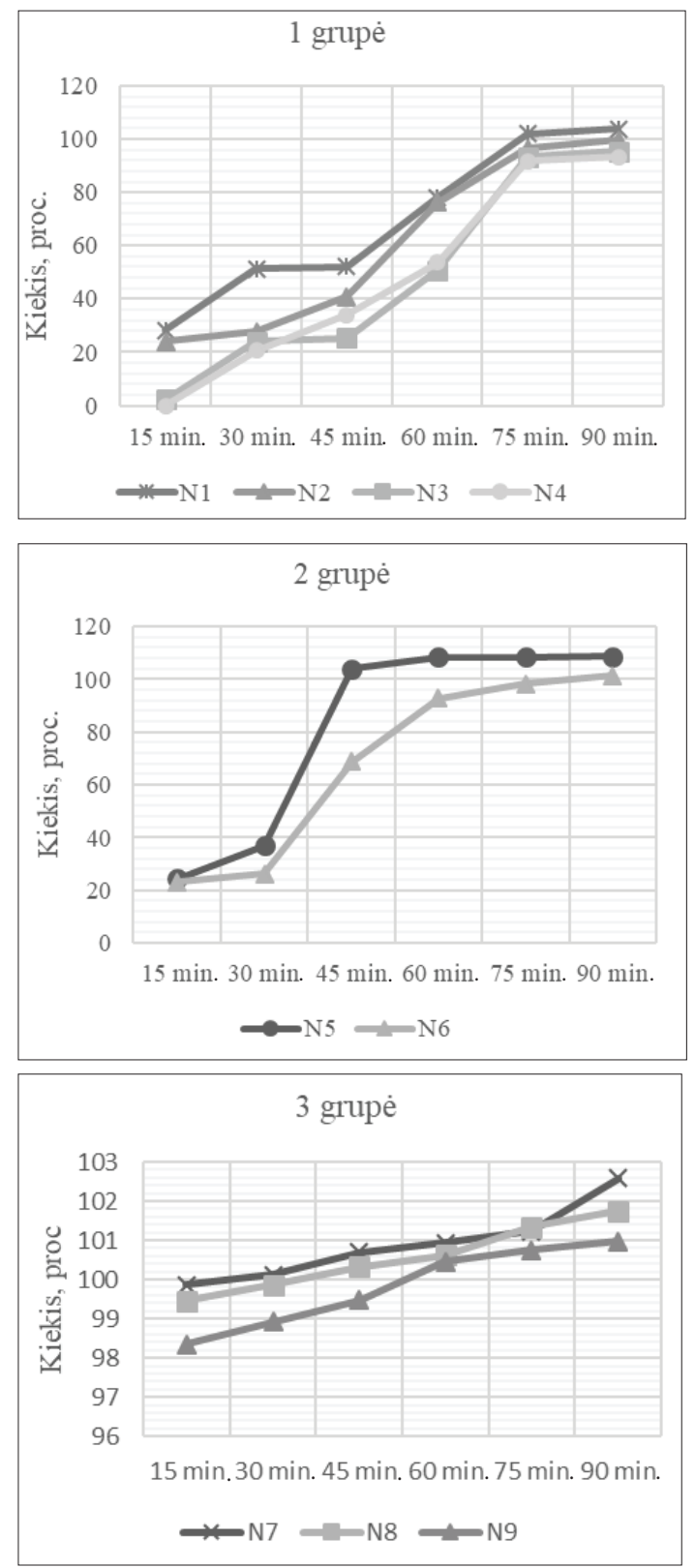

3 pav. Tirpimo testavimo rezultatai. 
3. Manitolis, gliukozė ir mikrokristalinè celiuliozė yra tinkami užpildai modeliuojant labai greito atpalaidavimo kapsules su diklofenako natrio druska.

\section{Literatūra}

1. Chuasuwan B, Binjesoh V, Polli JE, Zhang H, Amidon GL, Junginger $\mathrm{HE}$, et al. Biowaiver monographs for immediate release solid oral dosage forms: Diclofenac sodium and diclofenac potassium. J Pharm Sci 2009;98(4):1206-1219.

https://doi.org/10.1002/jps.21525

2. Cwiertnia B. Effect of water soluble carrier on dissolution profiles of diclofenac sodium. Acta Pol Pharm 2013;70(4):721-726.

3. Van Den Abeele J, Brouwers J, Mattheus R, Tack J, Augustijns P. Gastrointestinal behavior of weakly acidic BCS class II drugs in Man-Case study of diclofenac potassium. J Pharm Sci 2016;105(2):687-696. https://doi.org/10.1002/jps.24647

4. Dressman J, Butler J, Hempenstall J, Reppas Ch. The BCS: Where do we go from here? Pharm Technol 2001;5:68-76.

5. Polli JE, Yu LX, Cook JA, Amidon GL, Borchardt RT, Burnside BA, et al. Summary workshop report: biopharmaceutics classification system--implementation challenges and extension opportunities. J Pharm Sci 2004;93(6):1375-1381. https://doi.org/10.1002/jps.20064

6. Panakanti R, Narang AS. Impact of excipient interactions on drug bioavailability from solid dosage forms. Pharm Res 2012;29(10):2639-2659. https://doi.org/10.1007/s11095-012-0767-8

7. Aulton ME, Taylor K. Aulton's pharmaceutics: the design and manufacture of medicines. 2013; 894.

https://books.google.lt/books?hl=lt\&lr=\&id=rrtGKQxcoWIC \&oi $=$ fnd \&pg $=$ PA $187 \& d q=\# v=$ onepage $\& q \& f=$ false

8. Ullmann P. Practice update: Excipient selection for compounded pharmaceutical capsules: They're only fillers, right? AJP: The Australian J Pharm 2017;1164(98):78.

9. Palmer D, Levina M, Nokhodchi A, Douroumis D, Farrell T, Rajabi-Siahboomi AR. The influence of sodium carboxymethylcellulose on drug release from polyethylene oxide extended release matrices. AAPS Pharm Sci Tech 2011;12:862-871.

https://doi.org/10.1208/s12249-011-9648-4

10. Radojkovic B, Milić J, Calija B. Compounding of slow-release niacinamide capsules: feasibility and characterization. Int $\mathrm{J}$ Pharm Compd 2012;16(5):434-437.
11. Council of Europe. European Pharmacopoeia. In: supplement 6.1. Strasbourg: Council of Europe 2007.

12. Nagel KM, Peck GE. Investigating the effects of excipients on the powder flow characteristics of theophylline anhydrous powder formulations. Drug Dev Ind Pharm 2003;29(3):277287.

https://doi.org/10.1081/DDC-120018201

\section{MODELING AND QUALITY ASSESMENT OF DICLOFENAC SODIUM CAPSULES}

\section{Paškevičiūtė, A. M. Inkènienė, K. Ramanauskienė}

Keywords: diclofenac sodium, excipients, dissolution test, disintegration test, capsules, carboxymethylcellulose sodium.

\section{Summary}

Diclofenac sodium is a poorly water soluble non-steroidal anti-inflammatory drug. It is relevant to produce slowly dissolving capsules with diclofenac sodium, to avoid irritating effect on gastrointestinal tract mucosa and to ensure the solubility of diclofenac salt in gastrointestinal fluids. Capsules, which was a chosen pharmaceutical form for this study, is one of the most commonly used peroral pharmaceutical forms. Choosing the right excipients for the production of solid pharmaceutical forms is important to ensure the appropriate kinetics of drug substance dissolution. In the composition of the formulation, D-mannitol, D-glucose and a mixture of microcrystalline cellulose were used as fillers. Carboxymethylcellulose sodium was used in a formulation as a prolongator of the process of active drug substance release. Disintegration and dissolution tests were performed according to the methods provided by European Pharmacopoeia. The quantity of diclofenac sodium was determined by the spectrophotometric method. Capsules of 9 different compositions, containing carboxymethylcellulose sodium (0-35\%) were produced in order to prolong the release of an active drug substance. The results of this study proved, that carboxymethylcellulose is an appropriate excipient for prolonging the release of an active drug substance. Diclofenac sodium release and disintegration rate depends on the quantity of carboxymethylcellulose sodium in a capsule.

Correspondence to: asta.inkeniene@go.kauko.lt

Gauta 2019-10-28 